\title{
Potensi Fungisida Perlakuan Benih terhadap Perenosclerospora sp. Penyebab Penyakit Bulai Jagung
}

\author{
The Potential of Fungicide-treated Seed against Peronosclerospora sp. \\ as the cause of Downy Mildew Disease in Maize
}

\author{
Author(s): Ahmad Ilham Tanzil ${ }^{(1) *}$; Hari Purnomo ${ }^{(1)}$ \\ (1) Universitas Jember \\ * Corresponding author: aitanzil@unej.ac.id
}

\begin{abstract}
ABSTRAK
Jamur patogen Perenosclerospora sp. merupakan penyakit penting pada tanaman jagung. Dampak yang ditimbulkan dapat menimbulkan kerugian hingga $100 \%$. Penelitian ini bertujuan untuk mengetahui pengaruh bahan aktif fungisida sebagai perlakuan benih dalam mengendalikan penyakit bulai (Perenosclerospora $\mathrm{sp}$.) pada tanaman jagung. Penelitian dilaksanakan dengan diawali menanam tanaman jagung yang diinokulasi bulai sebagai tanaman spreader (sumber inokulum alami) dan pembatas antar perlakuan. Selanjutnya saat tanaman border sudah terinfeksi bulai baru ditanam benih perlakuan yang sudah dicampur dengan bahan aktif fungisida. Penelitian disusun dalam rancangan acak lengkap dengan delapan perlakuan dengan tiga ulangan. Perlakuan terdiri atas kontrol tanpa fungisida (P0), dimetomorf (P1), dimetomorf + piraklostrobin $(\mathrm{P} 2)$, fenamidon $(\mathrm{P} 3)$, fenamidon dan propamokarb hodroklorida (P4), metalaksil (P5), mefenoksam (P6), dan fluopikolid+propineb (P7). Hasil penelitian menunjukkan perlakuan kontrol lebih bagus dalam meningkatkan daya kecambah dibandingkan dengan menggunakan fungisida. Benih jagung yang diberikan perlakukan bahan aktif dimetomorf + piraklostrobin memiliki potensi yang paling tinggi dalam menekan keterjadian penyakit bulai pada jagung manis dan mampu meningkatkan pertumbuhan tinggi tanaman jagung yang dibandingkan perlakuan lainnya.
\end{abstract}

Kata Kunci:

fungisida;

seed treatment;

Peronosclerospora

sp.;

jagung;

penyakit bulai.

\section{Keywords:}

fungicide;

seed treatment;

Peronosclerospora sp.;

maize;

downy mildew.

\section{ABSTRACT}

The pathogenic fungus Perenosclerospora sp. is an important disease in maize. The impact caused can make losses of up to 100\%. This study aims to determine the effect of seed treatment fungicide active ingredients in controlling downy mildew (Perenosclerospora sp.) in maize. The research was conducted by starting with planting maize inoculated with downy mildew as a spreader plant (a source of natural inoculum) and dividing between treatments. When the border plants have been infected with downy mildew, seeds treated with active fungicidal ingredients were then planted. The study was arranged in a completely randomized design with eight treatments and three replications. The treatments consisted of control without fungicide $(P 0)$, dimetomorph $(P 1)$, dimetomorph + piraklostrobin $(P 2)$, fenamidone (P3), fenamidone and propamocarb hodrochloride (P4), metallaxyl (P5), mefenoxam (P6), and fluopicolid + propineb (P7). The results showed that the control treatment was better at increasing germination than using fungicides. Maize seeds treated with the active ingredient dimetomorph + piraklostrobin had the highest potential in suppressing the incidence of downy mildew in sweet corn. In addition, the treatment of seeds with a mixture of active ingredients was able to increase the height growth of maize plants compared to other treatments. 


\section{PENDAHULUAN}

Jagung merupakan komoditas bernilai ekonomis yang tinggi karena dapat dimanfaatkan sebagai sumber pangan karbohidrat terbesar kedua setelah beras selain itu dapat menjadi sumber pakan hewan. Saat ini kebutuhan jagung nasional belum sepenuhnya tercukupi. Hal ini disebabkan karena kurangnya produksi jagung nasional diakibatkan karena beberapa faktor. Salah satunya yaitu serangan bulai jagung akibat jamur patogen Peronosclerospora sp. (Jatnika et al., 2013). Hikmahwati et al. (2019) mengatakan bahwa gejala serangan bulai jagung mampu mengakibatkan tanaman jagung tumbuh kerdil, klorosis atau kehilangan zat hijau daun yang pada akhirnya mengakibatkan kematian sebelum jagung dapat berproduksi. Hal tersebut selaras dengan pernyataan (Setyawan et al., 2016) bahwa penyakit ini dapat mengakibatkan kegagalan panen jagung hingga $100 \%$, bahkan serangan bulai ini sudah menyebar hingga ke seluruh pelosok Indonesia hingga dunia khususnya pada jagung lokal yang rentan terhadap penyakit tersebut.

Berbagai cara pengendalian telah banyak dilakukan petani. Namun seiring berjalannya waktu, penyakit bulai mulai menimbulkan banyak ras baru. Oleh sebab itu perlu dilakukan alternatif pengendalian dengan pemanfatan seed treatment. Penelitian difokuskan pelapisan benih jagung dengan Fungicide Seed Treatment (FST) untuk mengendalikan serangan bulai jagung. Teknologi FST diharapkan dapat mengurangi dan mencegah dampak serangan bulai jagung sehingga dapat meningkatkan produktivitas jagung secara optimal.

\section{METODOLOGI}

Penelitian dilaksanakan di Laboratorium Agroteknologi, Fakultas Pertanian, Universitas Jember dan Lahan Pertanian di Kelurahan Tegalgede,
Kecamatan Sumbersari, Kabupaten Jember. Waktu penelitian dimulai pada bulan Agustus 2020 sampai dengan Desember 2020.

\section{Penanaman Tanaman Border dan Spreader}

Tanaman border dan spreader diperlukan sebagai pembatas antar plot perlakuan dan sebagai media penularan atau infeksi secara alami. Adapun benih jagung kategori rentan bulai yang ditanam yaitu varietas Pioneer P27. Tanaman border harus ditanam terlebih dahulu kemudian diinokulasikan dengan spora bulai jagung. Hal tersebut dilakukan dengan harapan agar nantinya ketika sudah muncul gejala akan dapat memberikan dampak sebagai sumber infeksi pada tanaman perlakuan.

\section{Isolasi Spora Bulai sebagai Sumber Inokulum}

Sebelum aplikasi seedtreatment perlu mendapatkan sumber inokulum bulai sebagai sumber infeksi untuk tanaman border. Sumber inokulum didapatkan dari lahan jagung yang bergejala bulai. Adapun daerah pengambilan sampel spora bulai yaitu di daerah Ledokombo, Jember dengan titik koordinat $8^{\circ} 08^{\prime} 05.3^{\prime \prime S}$ $113^{\circ} 52^{\prime 29} 3^{\prime \prime E}$. Adapun varietas jagung yang ditanam yaitu jagung Pioneer P21 yang telah berumur kurang lebih 1 bulan setelah tanam.

\section{Inokulasi Spora Bulai pada Tanaman Border dan Spreader}

Setelah inokulum bulai didapatkan dan dikumpulkan. Langkah selanjutnya adalah proses infeksi atau inokulasi spora bulai sebagai sumber inokulum. Proses yang harus dilakukan antara lain memanen spora bulai dengan cara memotong bagian daun yang bergejala ( $1 / 2$ sakit dan $1 / 2$ sehat) kemudian dimasukkan kedalam air bersih. Kemudian daun dikocok agar spora bisa rontok ke dalam air. Larutan spora ditampung di sprayer untuk disemprotkan 
ke tanaman border setiap hari pada saat tanaman berumur 7-20 HST. Adapun waktu penyemprotan pada saat dini hari (sebelum matahari terbit) atau sebelum magrib (menjelang matahari terbenam). Hal ini dilakukan agar spora tidak mati karena terpapar sinar matahari.

\section{Formulasi Bahan Aktif Perlakuan Benih}

Tahapan pembuatan fungisida seedtreatment pada benih jagung dimulai dengan menimbang bahan sesuai takaran pada Tabel 1 berikut. Setelah ditimbang benih dicampur dengan larutan bahan aktif pestisida. Selanjutnya setelah dicampur kemudian diletakkan wadah yang telah diberi label agar tidak tertukar.

Tabel 1. Formulasi bahan pada setiap perlakuan

Table 1. Formulation of ingredients dosage in each treatment

\begin{tabular}{|c|c|c|c|c|c|c|c|c|}
\hline \multirow[t]{2}{*}{$\begin{array}{c}\text { Bahan } \\
\text { Ingredient }\end{array}$} & \multicolumn{8}{|c|}{$\begin{array}{c}\text { Perlakuan } \\
\text { Treatments }\end{array}$} \\
\hline & P0 & P1 & P2 & P3 & $\mathrm{P} 4$ & P5 & P6 & P7 \\
\hline $\begin{array}{l}\text { Jagung } \\
\text { maize }\end{array}$ & $50 \mathrm{~g}$ & $50 \mathrm{~g}$ & $50 \mathrm{~g}$ & $50 \mathrm{~g}$ & $50 \mathrm{~g}$ & $50 \mathrm{~g}$ & $50 \mathrm{~g}$ & $50 \mathrm{~g}$ \\
\hline Dimetomorf & - & $0,125 \mathrm{~g}$ & - & - & - & - & - & - \\
\hline $\begin{array}{l}\text { Dimetomorf + } \\
\text { Piraklostrobin }\end{array}$ & - & - & $0,25 \mathrm{ml}$ & - & - & - & - & - \\
\hline Fenamidon & - & - & - & $0,3 \mathrm{ml}$ & - & - & - & - \\
\hline $\begin{array}{l}\text { Fenamidon + } \\
\text { Propamokarb } \\
\text { Hodroklorida }\end{array}$ & - & - & - & - & $1 \mathrm{ml}$ & - & - & - \\
\hline Metalaksil & - & - & - & - & - & $0,85 \mathrm{ml}$ & - & - \\
\hline Mefenoksam & - & - & - & - & - & - & $0,125 \mathrm{ml}$ & - \\
\hline $\begin{array}{l}\text { Fluopikolid + } \\
\text { Propineb }\end{array}$ & - & - & - & - & - & - & - & $1 \mathrm{~g}$ \\
\hline Air & $5 \mathrm{ml}$ & $5 \mathrm{ml}$ & $5 \mathrm{ml}$ & $5 \mathrm{ml}$ & $5 \mathrm{ml}$ & $5 \mathrm{ml}$ & $5 \mathrm{ml}$ & $5 \mathrm{ml}$ \\
\hline
\end{tabular}

Pengamatan di lapangan dan di konidia dan konidiofor. Parameter laboratorium pengamatan morfologi dan morfometri

Benih yang telah diberi perlakuan seed treatment ditanam di lahan saat tanaman border yang sudah diinokulasi bulai jagung mulai menunjukan gejala. Benih jagung yang digunakan dalam setiap perlakuan adalah $50 \mathrm{~g}$ berat kering. Penelitian menggunakan Rancangan Acak Lengkap Kelompok (RAL) dengan 8 macam perlakuan serta 3 ulangan. Dari setiap perlakukan dengan 3 ulangan. Setiap ulangan terdiri dari 20 benih jagung. Adapun pengamatan yang diamati yaitu daya kecambah benih pada 5 HST untuk mengetahui tingkat viabilitas benih perlakuan setelah ditanam, pengamatan intensitas serangan penyakit bulai, tinggi tanaman.

Pengamatan morfologi dan morfometri dilakukan pada 30 buah dilihat berdasarkan bentuk konidia, dimensi konidia dan konidiofor, jumlah percabangan, serta ketebalan dinding sel (Widiantini et al., 2018). Pengamatan kejadian penyakit dilakukan setiap 7 hari sekali sampai 28 hari setelah tanam (HST) dan selanjutnya persentase tanaman jagung yang menunjukkan gejala penyakit bulai dapat dihitung (Adhi et al., 2019).

\section{HASIL DAN PEMBAHASAN \\ Daya Kecambah Benih}

Pada saat 5 HST dilakukan pengamatan uji daya kecambah pada benih seed treatment. Hasil uji daya kecambah tersaji pada Tabel 2. Hasil uji daya kecambah menunjukkan bahwa seed treatment yang telah diaplikasikan mempengaruhi daya kecambah benih. Berdasarkan uji daya kecambah benih 
diketahui hasil terbaik pada perlakuan kontrol. Hal ini selaras dengan pernyataan (Rachman et al., 2019) bahwasannya perlakuan kontrol pada penelitian fungsida seedtreatment memiliki pengaruh yang baik dibandingkan perlakuan dengan pemberian bahan aktif fungisida. Perlakuan benih dengan fungisida dapat menurunkan daya kecambah. Hal tersebut disebabkan karena efek perlakuan benih oleh fungsida dipengaruhi oleh kondisi benih. Setiyowati et al. (2007) menyatakan bahwa kondisi benih saat diberikan perlakuan fungisida berdampak fitotoksisitas pada fungisida yang digunakan.

Tabel 2. Hasil uji daya kecambah

Table 2. The results of germination test

$\begin{array}{cc}\text { Perlakuan } & \text { Daya } \\ \text { Treatments } & \text { kecambah } \\ & \text { Germination }\end{array}$

$(\%)$

\begin{tabular}{ll}
\hline Kontrol & $30,0 \mathrm{~b}$ \\
Dimetomorf & $20,0 \mathrm{ab}$ \\
Dimetomorf + Piraklostrobin & $23,3 \mathrm{ab}$ \\
Fenamidon & $13,3 \mathrm{ab}$ \\
Fenamidon + Propamokarb & $13,3 \mathrm{ab}$ \\
Hodroklorida & \\
Metalaksil & $10,0 \mathrm{a}$ \\
Mefenoksam & $13,3 \mathrm{ab}$ \\
Fluopikolid + Propineb & $16,6 \mathrm{ab}$ \\
\hline
\end{tabular}

Keterangan: angka rata-rata yang diikuti huruf yang sama menunjukkan tidak berbeda nyata menurut uji jarak berganda Duncan

Note: the average number followed by the same letter shows insignificant differences according to Duncan's multiple rate test

\section{Intensitas Seragan Penyakit}

Pada saat 28 HST dilakukan pengamatan uji intensitas penyakit pada percobaan benih seed treatment. Hasil uji intensitas tersaji pada Tabel 3. Hasil uji intensitas penyakit menunjukkan bahwa seed treatment yang telah diaplikasikan mempengaruhi keparahan penyakit bulai Intensitas serangan bulai lebih banyak terjadi pada perlakuan kontrol (tanpa diberikan fungisida). Bahan aktif Dimetomorf, Dimetomorf+Piraklostrobin,
Fenamidon+Propamokarb Hodroklorida, Metalaksil,

Mefenoksam, Fluopikolid+Propineb terbukti mampu menurunkan serangan bulai. Hal ini disebabkan benih tidak terlindungi bahan aktif fungisida yang dapat menghambat ataupun mencegah penetrasi dari patogen penyebab bulai jagung. Perlakuan benih dapat meningkatkan mutu dan produksi benih serta mengendalikan penyakit bulai pada jagung (Sonhaji et al., 2013). Aplikasi pestisida seedtreatment mampu mempengaruhi aktivitas jamur patogen sehingga penyakit bulai dapat dihindarkan sejak dini. Menurut Swibawa et al. (2017) bahwa aplikasi pestisida dapat menurunkan kelimpahan mikroorganisme.

Tabel 3. Intensitas serangan penyakit

Table 3. Intensity of disease attacks

\begin{tabular}{lc}
\multicolumn{1}{c}{ Perlakuan } & $\begin{array}{c}\text { Intensitas serangan } \\
\text { Intensity of disease } \\
\text { attacks }\end{array}$ \\
\hline Kontrol & $7,50 \mathrm{~b}$ \\
Dimetomorf & $2,11 \mathrm{a}$ \\
Dimetomorf + & $1,05 \mathrm{a}$ \\
Piraklostrobin & \\
Fenamidon & $4,37 \mathrm{ab}$ \\
Fenamidon + & $2,98 \mathrm{a}$ \\
Propamokarb & \\
Hodroklorida & \\
Metalaksil & \\
Mefenoksam & 3,05 a \\
Fluopikolid + Propineb & 2,88 a \\
\hline Keterangan: angka rata-rata yang diikuti huruf \\
yang sama menunjukkan tidak berbeda \\
nyata menurut uji jarak berganda Duncan \\
Note: the average number followed by the same \\
letter shows insignificant differences \\
according to Duncan's multiple rate test
\end{tabular}

\section{Pertumbuhan Tinggi Tanaman}

Tinggi tanaman dilihat pengaruhnya untuk mengetahui antar perlakuan. Tabel 4 merupakan rerata dari tinggi tanaman pada saat pengamatan 28 HST. Dari hasil tersebut dapat diketahui tinggi tanaman paling rendah pada perlakuan control. Hal ini disebabkan pada perlakuan kontrol terdapat banyak serangan bulai. Karena bulai dapat mengakibatkan tanaman kerdil dan perubahan warna daun menjadi 
kekuningan dengan banyak spora bulai di bagian daunnya. Penyakit bulai disebabkan oleh patogen Peronosclerospora sp. yang menyerang jagung muda dengan gejala local dan sistemik sehingga sering sering sekali menyebabkan gagal panen akibat tongkol yang tidak terbentuk (Muis et al., 2018). Kerusakan jagung akibat penyakit bulai terjadi pada tanaman jagung umur muda
(10-15) dapat mencapai $100 \%$ terutama pada varietas yang peka atau rentan (Talanca, 2013). Hal tersebut diperkuat dengan pernyataan Ulhaq \& Masnilah (2019) yang mengatakan bahwa P. maydis menginfeksi tanaman jagung pada umur 2-3 minggu, dengan tingkat kerusakan mencapai $80-100 \%$.

Tabel 4. Tinggi tanaman pada 28 HST

Table 4. Plant height at 28 days after planting

\begin{tabular}{lc}
\hline \multicolumn{1}{c}{ Perlakuan } & $\begin{array}{c}\text { Tinggi tanaman pada 28 HST } \\
\text { Treatments }\end{array}$ \\
\hline Kontrol & $17,0 \mathrm{a}$ \\
Dimetomorf & $29,3 \mathrm{bc}$ \\
Dimetomorf + Piraklostrobin & $31,5 \mathrm{c}$ \\
Fenamidon & $21,1 \mathrm{ab}$ \\
Fenamidon + Propamokarb Hodroklorida & $23,3 \mathrm{ab}$ \\
Metalaksil & $20,5 \mathrm{ab}$ \\
Mefenoksam & $22,9 \mathrm{ab}$ \\
Fluopikolid + Propineb & $23,8 \mathrm{ab}$ \\
\hline
\end{tabular}

Keterangan: angka rata-rata yang diikuti huruf yang sama menunjukkan tidak berbeda nyata menurut uji jarak berganda Duncan

Note: the average number followed by the same letter, in the same row, shows insignificant differences according to Duncan's multiple rate test

\section{Morfologi Spora Bulai}

Spora bulai diamati dengan cara mengambil daun yang bergejala. Kemudian di inkubasi semalam dengan larutan gula $10 \%$ dan disungkup agar menjaga kelembaban serta memudahkan dalam proses inokulasi. Saat dini hari, spora dipanen mengunakan kertas saring yang telah disterilisasi dan dicelupkan ke aquades steril. Spora dimasukkan ke dalam tube $15 \mathrm{~mL}$ yang berisi aquades steril agar lebih mudah dalam pengamatan. Pengamatan menggunakan mikroskop dengan ditambahkan lactofenolblue untuk mewarnai spora. Adapun hasil bulai yang diamati dapat dilihat di gambar berikut. 


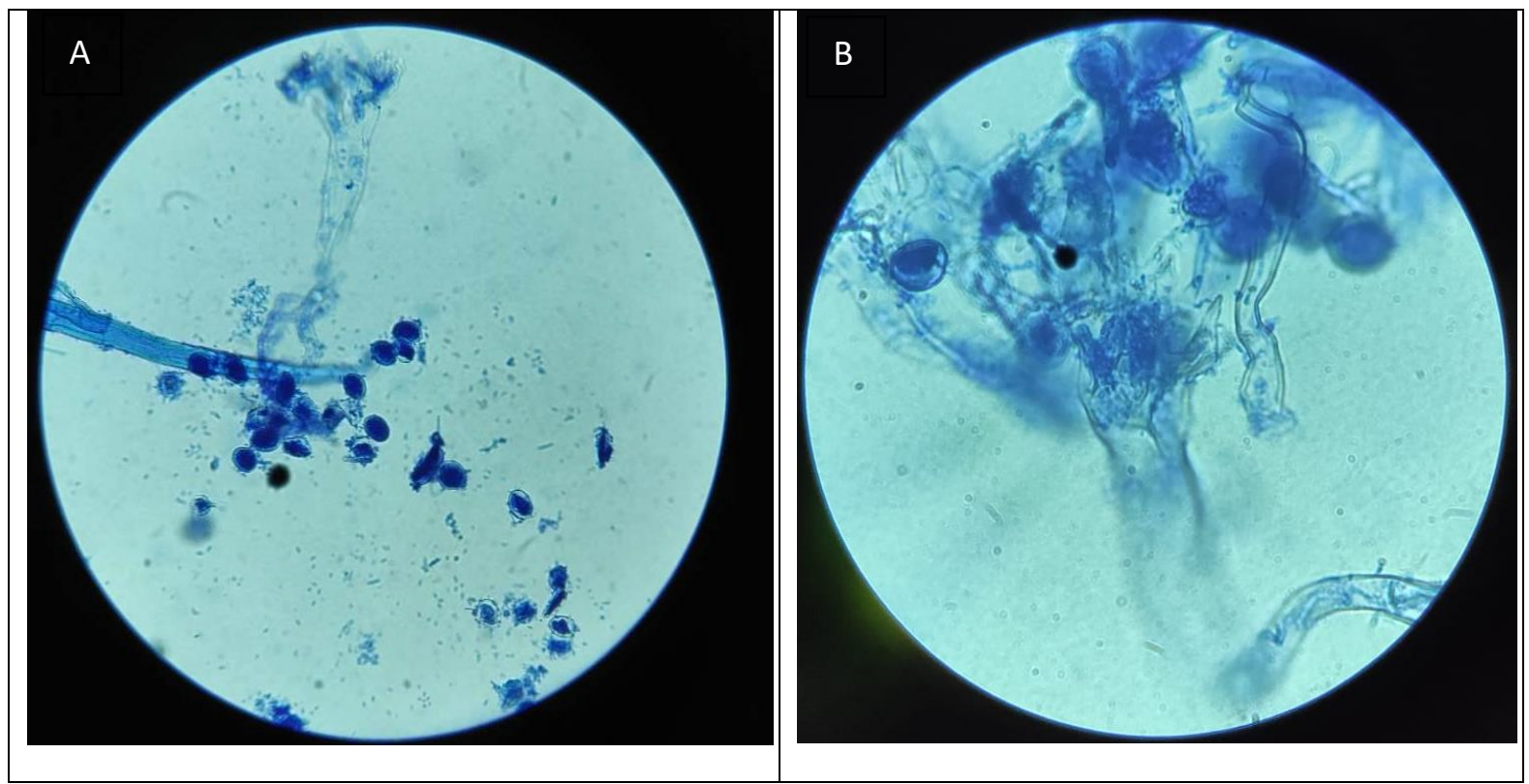

Gambar 1. Morfologi spora bulai

Figure 1. Morphology of downy mildew spores

Keterangan:

A. Morfologi konidia

B. Morfologi konidiofora

Information:

A. Morphology of conidia

B. Morphology of conidiophores

Berdasarkan hasil pengamatan, morfologi konidiofor bercabang-cabang sebagai tempat melekatnya konidia. Konidium cendawan P.maydis yang masih muda berbentuk bulat, sedangkan yang sudah masak dapat menjadi lonjong. Ukuran konidium 12-19 x 10-23 $\mu \mathrm{m}$ dengan rata-rata 19,2-17,0 $\mu \mathrm{m}$. Konidium P. phillipinesis lebih oval dengan diameter sekitar 14- 15 x 8-10 $\mu \mathrm{m}$ dan tumbuh membentuk bulu berkecambah (Talanca, 2013).

\section{KESIMPULAN}

Perlakuan benih jagung dengan fungisida memberikan dampak yang sangat bagus dalam hal pencegahan penyakit bulai dan pertumbuhan tanaman jagung. Berdasarkan hasil penelitian fungisida untuk perlakuan benih memiliki dampak menurunkan daya kecambah di awal tanam. Namun perlakuan fungisida dengan campuran bahan aktif dimetomorf dan piraklostrobin memiliki dampak

\begin{abstract}
menurunkan intensistas bulai dibandingkan perlakuan lainnya. Sedangkan pengaruh fungisida terhadap penambahan tinggi tanaman jagung berdampak sangat signifikan dibandingkan perlakuan kontrol yang banyak sekali serangan bulainya.
\end{abstract}

\section{DAFTAR PUSTAKA}

Adhi, S. R., Widiantini, F., \& Yulia, E. EQ (2019). Metode inokulasi buatan untuk menguji infeksi Peronosclerospora maydis penyebab penyakit bulai tanaman jagung. Jurnal Agro, 6(1), 77-85.

Hikmahwati, H., Kuswinanti, T., \& EQ Melina, M. (2019). Karakterisasi Molekuler Isolat-Isolat Penyebab Bulai (Peronosclerospora spp) Pada Tanaman Jagung Berbasis Simple Sequence Repeat (SSR). AGROVITAL: Jurnal Ilmu Pertanian, 3(1), 1. 
Jatnika, W., Abadi, A. L., \& Aini, Q. L. (2013). Pengaruh Aplikasi Bacillus sp. dan Pseudomonas Sp. terhadap Perkembangan Penyakit Bulai yang Disebabkan oleh Jamur Patogen Peronosclerospora Maydis pada Tanaman Jagung. Jurnal Hama Penyakit Tumbuhan, 1(4), 19-29.

Muis, A., Suriani, Kalqutny, S. H., \& EQ Nonci, N. (2018). Penyakit Bulai pada Tanaman Jagung dan Upaya Pengendaliannya. Deepublish.

Rachman, F., Sasmita, E. R., \& 尌 Wongsowijoyo, S. (2019). Pengaruh Pencucian Benih dengan Penambahan Fungisida terhadap Tingkat Serangan Penyakit Bulai, Pertumbuhan, dan Hasil Jagung Hibrida Varietas P27. Agrosains: Jurnal Penelitian Agronomi, 21(1), 16.

Setiyowati, H., Surahman, M., \& Wiyono, Q S. (2007). Pengaruh Seed Coating dengan Fungisida Benomil dan Tepung Curcuma terhadap Patogen Antraknosa Terbawa Benih dan Viabilitas Benih Cabai Besar (Capsicum annuum L.). Indonesian Journal of Agronomy, 35(3), 176182.

Setyawan, B., Suliansyah, I., Anwar, A., 尌 \& Swasti, E. (2016). Preliminary Trial of 11 New Hybrid Maize Genotype to the Resistance on Java Downy Mildew (Peronosclerospora maydis). International Journal on Advanced Science Engineering Information Technology, 6(2), 262264.

Sonhaji, M. Y., Surahman, M., Ilyas, S., 钽 \& Giyanto. (2013). Perlakuan Benih untuk Meningkatkan Mutu dan Produksi Benih serta Mengendalikan
Penyakit Bulai pada Jagung Manis. Jurnal Agronomi Indonesia, 41(3), 242-248.

Swibawa, I. G., Fityana, D., Septiani, L., 顽 Suharjo, R., \& Prasetyo, J. (2017). Dampak Aplikasi Fungsisida Perlakuan Benih Jagung Terhadap Kelimpahan Nematoda dan Artropoda Tanah. Prosiding Seminar Nasional Pengembangan Teknologi Pertanian, 1-8.

Talanca, A. H. (2013). Status Penyakit EQ Bulai pada Tanaman Jagung dan Pengendaliannya. Seminar Nasional Inovasi Teknologi Pertanian, 76-78.

Ulhaq, M. A., \& Masnilah, R. (2019). 钢 Pengaruh Penggunaan Beberapa Varietas dan Aplikasi Pseudomonas fluorescens untuk Mengendalikan Penyakit Bulai (Peronosclerospora maydis) pada Tanaman Jagung (Zea mays L.). Jurnal Pengendalian Hayati, 2(1), 1.

Widiantini, F., Pitaloka, D. J., Nasahi, C., E \&ulia, E. (2018). PerkecambahanPeronosclerospora spp. Asal Beberapa Daerah di Jawa Barat pada Fungisida Berbahan Aktif Metalaksil, Dimetomorf dan Fenamidon. Agrikultura, 28(2). 